\title{
MATERIAL FLOW ANALYSIS AND PLANT LAY-OUT OPTIMIZATION OF A MANUFACTURING SYSTEM
}

\author{
Francesco Longo, Giovanni Mirabelli, Enrico Papoff \\ Mechanical Department, University of Calabria, Italy, 87036, Via P. Bucci, Rende (CS) \\ f.longo@unical.it, g.mirabelli@unical.it, e.papoff@unical.it \\ www.ingegneria.unical.it/impiantiindustriali.htm
}

\begin{abstract}
The paper proposes the results of a research project developed by the authors in collaboration with a production system working in the field of manufacturing wood products. The first step of the project was an accurate analysis of the system and the design of new production documents in order to collect data about the system itself. The collected data have been used to propose an initial solution of plant lay-out. The second step of the project was the construction of a simulation model. The model has been used to find an optimal plant-layout configuration by means of genetic algorithms with the goal of material handling cost and shop order flow time minimization.
\end{abstract}

Keywords: Material Flow, Plant Lay-Out, Modeling \& Simulation, Genetic Algorithms, Optimization.

\section{INTRODUCTION}

One of the priority tasks of successful manufacturers is to design an efficient plant lay-out for guarantying low material handling costs, material flow improving, production bottlenecks reduction [5, 7].

Due to the high complexity of plant lay-out analyses and optimizations, considering the high stochastic nature of the main variables (e.g. the process and set-up times, market demand, queuing, downtimes, and so on) as well as the company requirements to have feasible solutions, it becomes easy to understand the inadequacy of traditional methodologies and approaches.

Among the computerized approaches to plant lay-out study the most important are ALDEP, CORELAP, RMA, CRAFT [21-35]. In addition, nowadays, further approaches using CAD software have been proposed [37-43].

It's important to stress that most of the traditional methodologies for plant lay-out study allow analyzing and evaluating some possible plant lay-out configurations by means of qualitative tools such as networks made up by nodes and arrows respectively representing departments and materials flows. Very often the approach is based on average transported quantities for defining materials flow and Euclidean distances for determining machines positions, without taking into consideration the previously mentioned system characteristics. These factors have a direct and strong impact on the materials flow and they must be considered in order to have an efficient material handling system and an efficient plant layout.

In this context the simulation plays a critical role as problem solving tool, that, can be used to test several and different scenarios and perform what-if analysis, taking into account the complexity of the systems under study and providing an accurate representation of the real world system [5].

The paper focalizes on the key points of a project developed in collaboration with a production system working in the sector of wood frames manufacturing. The company manufactures different products families, e.g. doors, windows, shutters and the market demand prevalently comes from building industries.

Currently factory buildings, used for production activities, take up about 1200 squares meters. Plant lay-out organization is characterized by an irregular disposition of production machines. This situation causes material flow complications, excessive material handling, high work in process and inefficient manpower utilization as well.

Actually these problems are considerably amplified by the lack of space; in fact, the factory building is completely inadequate for materials flows.

To give an answer to plant lay-out problems the top management has foreseen an enlargement of factory buildings, the material flow analysis and the plant lay-out optimization, in collaboration with Industrial Engineering Section of Mechanical 
Department of University of Calabria. The fundamental steps of the research project can be summarized as follows:

- system preliminary analysis;

- implementation of new production documents;

- data collection;

- material flow analysis and initial plant lay-out solution;

- implementation of the production system simulation model;

- plant lay-out analysis and optimization by means of genetic algorithms;

- material handling costs analysis;

- flow time and work in process analysis.

\section{PRODUCTION SYSTEM ANALYSIS}

In accordance with the production planning experts it was decided to design two documents, respectively called "production sheet" and "working sheet" aiming to collect data for the plant lay-out study and optimization and to guarantee a simple way for collecting information about the system for performance system monitoring and improving [1].

The production sheet (see fig. 1) has been realized for collecting data relatively to each phase of manufacturing process. In particular data regarding manufactured item name, machine name, date and time of start work, date and time of end work, number of manufactured items, identifying code of raw materials, identifying code of raw materials suppliers, rejected pieces, worker's sign, responsible sign and annotations.

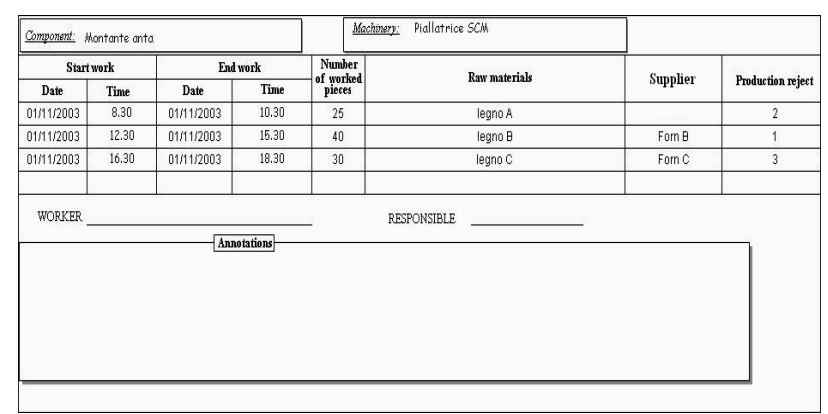

Fig. 1 - Production Sheet

The working sheet (see fig. 2) summarizes all the information collected by means of production sheets. For each manufacturing step it gives the possibility to compare foreseen and effective quantities, foreseen production time and effective production time and keep under control work in process. This tool assures continuous system monitoring and collected data have further been used for the initial plant lay-out design.

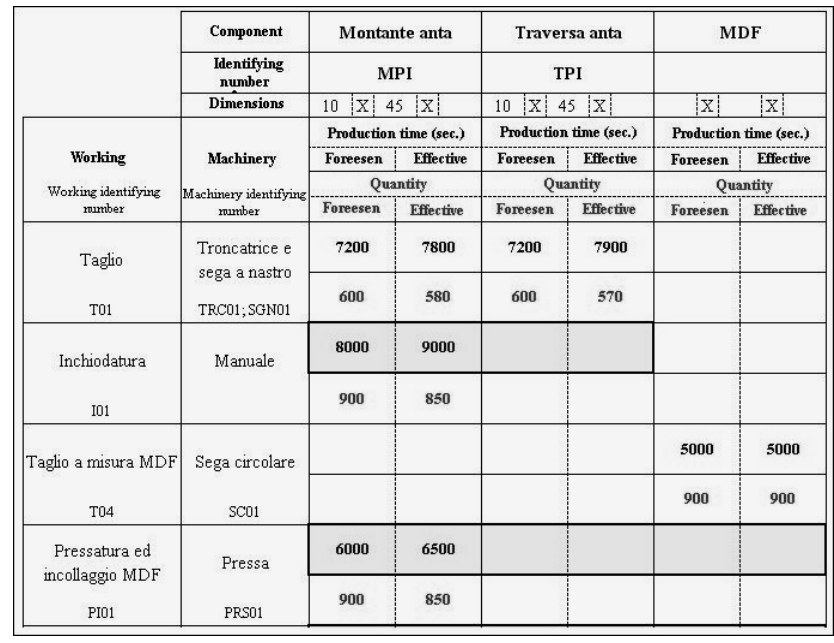

Fig. 2 - Working Sheet

In Order to reach the first objective of the work the design of an initial plant lay-out - it was necessary to analyze the materials flow generated by the different products families.

First of all it has been proposed a new subdivision of machines in departments, identifying 8 different departments:

- Cut and Shaving Department (1)

- Numerical Control Machines Department (2)

- Press and Manual Work Department (3)

- Calibration Department (4)

- Assembly 1 Department (5)

- Painting Department (6)

- Drying Department (7)

- Assembly 2 Department (8)

Each products family has been studied (in terms of material flow analysis) by means of flow charts, (the fig. 3 shows the flow chart of the products family $8 \mathrm{~B} 2 \mathrm{BN}$ ).

The first column of the flow chart reports the departments, the second row reports the product main components. For instance, the component A3 passes through the departments following the order: (1)-(3)-(2)-(4)-(2)-(5)-(6). Components A1, A2, A3 will be assembled to form the sub-assembly $\mathrm{A}$. The sub-assemblies A, B, C, will form the product $8 \mathrm{~B} 2 \mathrm{BN}$.

The meaning of the term $\mathrm{PC}$ is pieces for each finished product unity and AMQ is the monthly average quantity handled in the plant.

The initial plant lay-out solution has been designed using the traditional traffic intensity methodology, keeping into account the type of material handling systems (hand operated dollies, which capacity strictly depends on the type and number of transported components).

Fig. 4 shows the initial plant lay-out in output by the intensity traffic methodology and implemented 
in the simulation model, (for what concern the simulation model refer to next paragraphs).

As previously said the traffic intensity methodology allows analyzing and evaluating some possible plant lay-out configurations by means of qualitative tools such as networks made up by nodes and arrows respectively representing departments and materials flow.

Once again it's important to stress that such a type of approach is based on average transported quantities without taking into consideration market demand trend and variability, stochastic process and set-up times, queuing, downtimes and so on. These factors have a direct impact on the materials flow and they must be taken into account in order to have an efficient disposition of machines and materials.

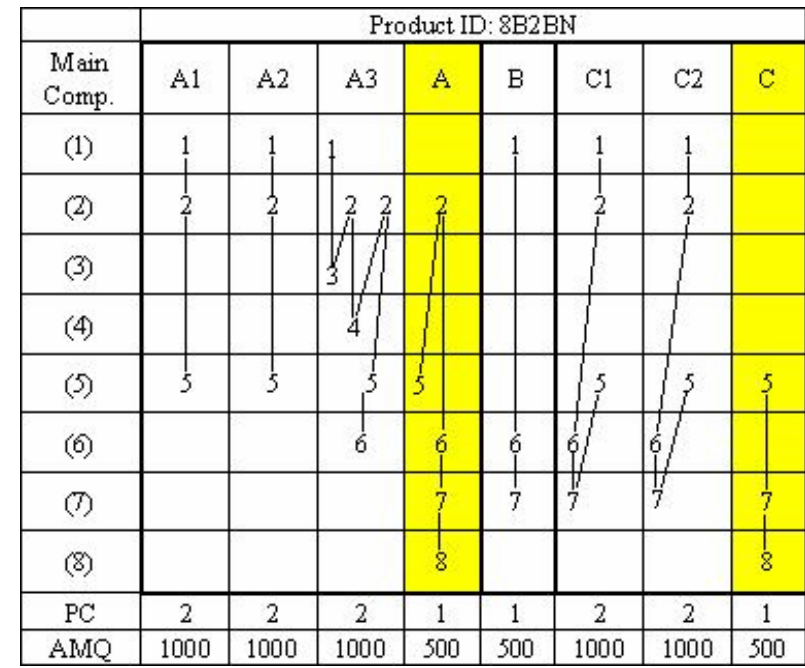

Fig. 3 - Flow Chart of the Products Family 8B2BN

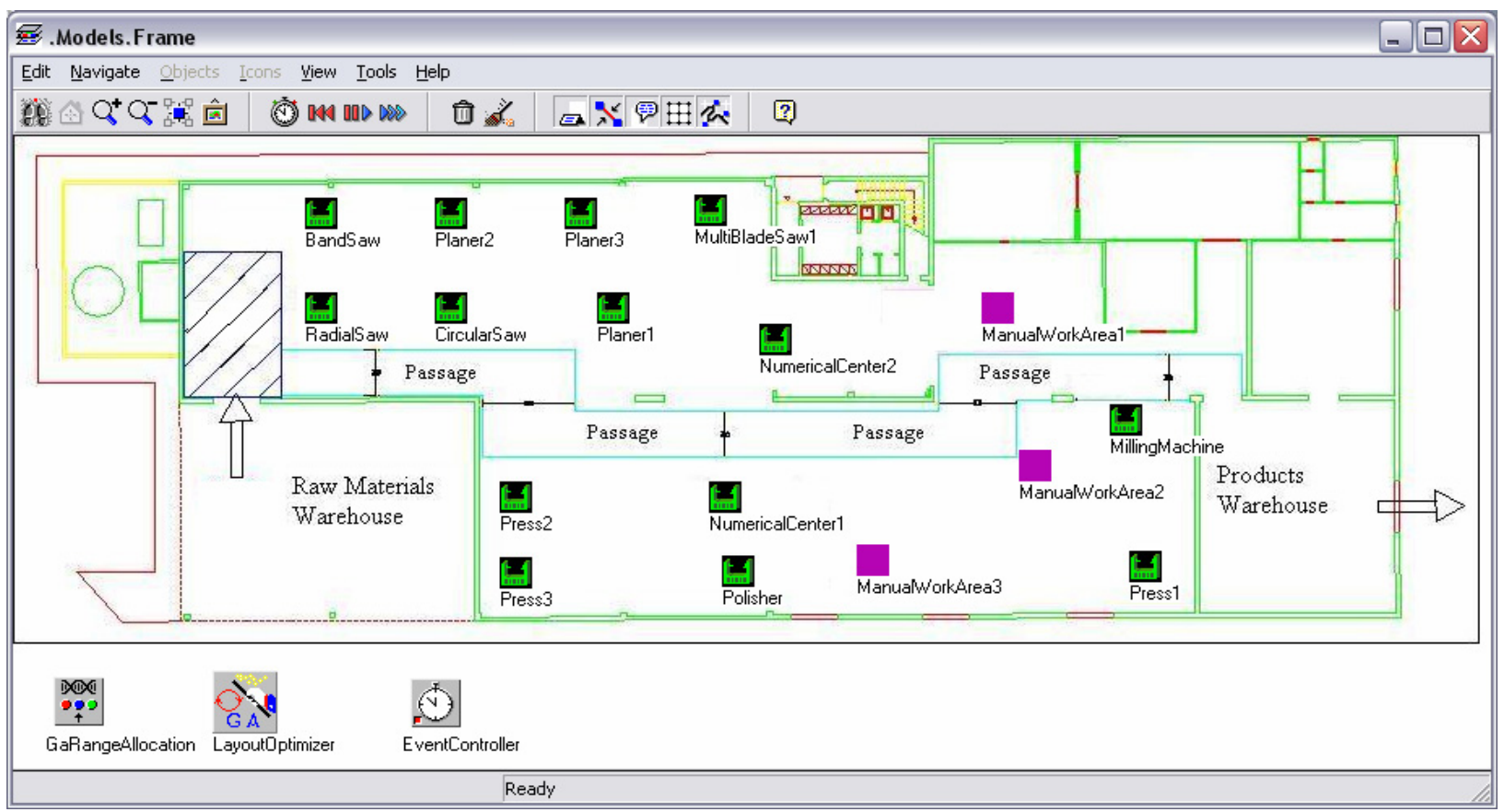

Fig. 4 - Initial Plant Lay-Out

\section{THE SIMULATION MODEL}

To improve the initial plant lay-out, evaluated using the traditional traffic intensity methodology, the authors have been developed a simulation model of the production system, using discrete event simulation software. The fundamental idea is to use the simulation model for testing different scenarios regarding plant lay-out solutions.

The data implemented in the model regard:

- market demand trend and variability;

- production and set-up times (collected using the production sheets);

- products flow charts;

- type and dimensions of machines;

- space required for human movements around machines;

- space required for material handling systems movements around each machine;

- space required for machinery maintenance.

An example of data collection is given in table 1 for the planer 1 machine (see also fig. 4).

The approach proposed by the authors improves the initial plant lay-out focusing on the use of genetic algorithms (GAs).

The GAs are implemented in the simulation software as generic objects that can be used in optimization problems. For what concern plant layout analysis the simulation software offers, as 
optimization tool, the lay-out optimizer object (see fig. 4). Once again this object doesn't consider some real aspects that play, for sure, a critical role.

Table 1. Data Collection for Planer 1 Machine

\begin{tabular}{|l|l|}
\hline Type & Planer machine \\
\hline Brand & SCM \\
\hline Model & Compact 23 \\
\hline Max Dimensions & $3,80 \mathrm{x} 1,40 \mathrm{~m}$ \\
\hline Space required (right side) & $1.50 \mathrm{~m}$ \\
\hline Space required (left side) & $2.00 \mathrm{~m}$ \\
\hline Space required (front side) & $3.00 \mathrm{~m}$ \\
\hline Space required (rear side) & $0.00 \mathrm{~m}$ \\
\hline Total space required, left-right & $4.90 \mathrm{~m}$ \\
\hline Total space required, front-rear & $6.80 \mathrm{~m}$ \\
\hline Max area (m ${ }^{2}$ ) & $33.32 \mathrm{~m}^{2}$ \\
\hline In material direction & front \\
\hline Out material direction & rear \\
\hline Type of work & $\begin{array}{l}\text { Shaving and } \\
\text { profiling }\end{array}$ \\
\hline
\end{tabular}

The object considers the Euclidean distance between machines as well as doesn't take into account constrains due to the factory building.

A new based-GAs object has been designed and implemented using the simulation language provided by the software (simple++) writing different subroutines that consider all the characteristics previously mentioned [3]. The object designed is completely scalable and can be consequently re-used for similar applications.

\section{VERIFICATION VALIDATION \& ACCREDITATION}

As reported in the $D o D V V \& A$ Recommended Practice Guide [8] the Validation, Verification \& Accreditation of a simulation model can be defined as follows:

"Verification is the process of determining that a model implementation accurately represents the developers' conceptual description and specifications" [8].

"Validation is the process of determining the degree to wich a model is an accurate representation of the real world from the perspective of the intended uses of the model", [8].

"Accreditation is the official certification that a simulation model is acceptable for use for a specific purpose. It is a decision that a specific simulation model can be used for specific application", [8].

Obviously some preliminary analysis was made for Validation, Verification and Accreditation (VV\&A) of the simulation model [5]. Simulation carried out in this first phase aims to evaluate the optimal length of the simulation runs and validate the model by checking obtained results [1].

It's extremely clear that the production system analyzed is a non-terminating system, in other words the duration of a simulation run is not a-priori fixed. The first objective in this type of simulation model is to evaluate the optimal length of a simulation run. To reach this purpose the Mean Square pure Error Analysis (MSpE) has been used. Considering that the attention is focalized on materials flow and plant lay-out optimization, the mean shop order flow time was chosen as performance index in order to establish, by means of MSpE, the optimal simulation run length. The shop order reports all the information and characteristics of the items to be manufactured as, for instance, number of items, bill of materials, operations plan, quality controls and so on. The shop order flow time is defined as the difference between the shop order exit time from the system (all the items have been manufactured) and the shop order entrance time (all the raw materials are ready to be worked).

Figure 5 shows that the flow time Mean Square pure Error reduction becomes negligible after 140 days. As recommended by the theory of the Mean Square pure Error analysis, the optimal simulation run length has been chosen equal to 140 days.

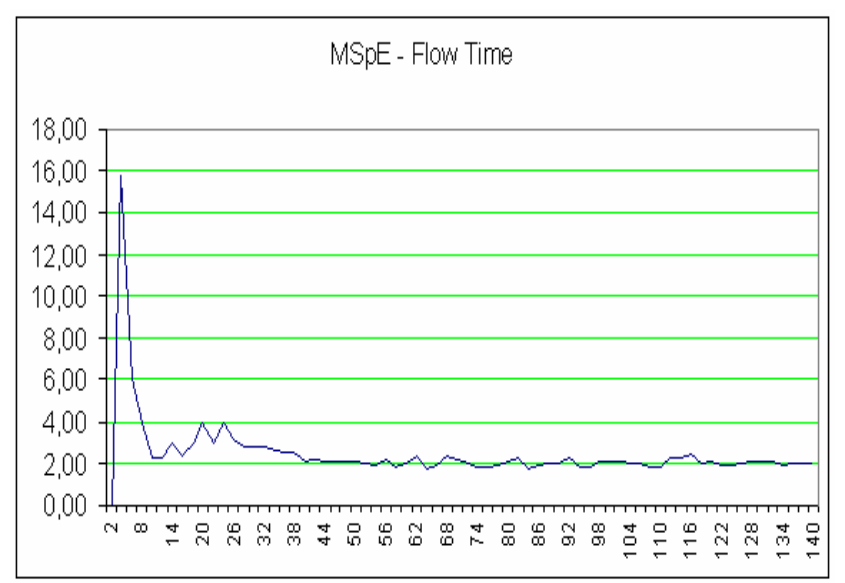

Fig. 5 - MSpE Analysis for simulation run length

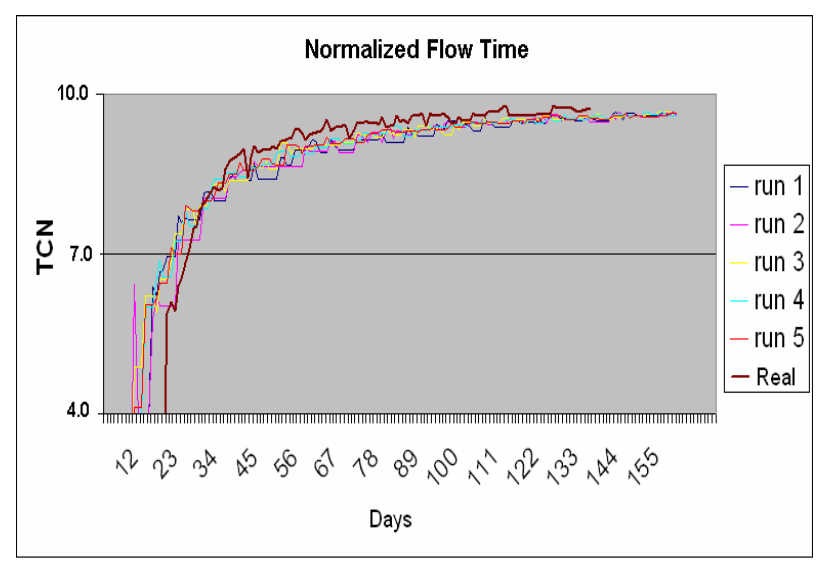

Fig. 6 - Flow Time Face Validation 


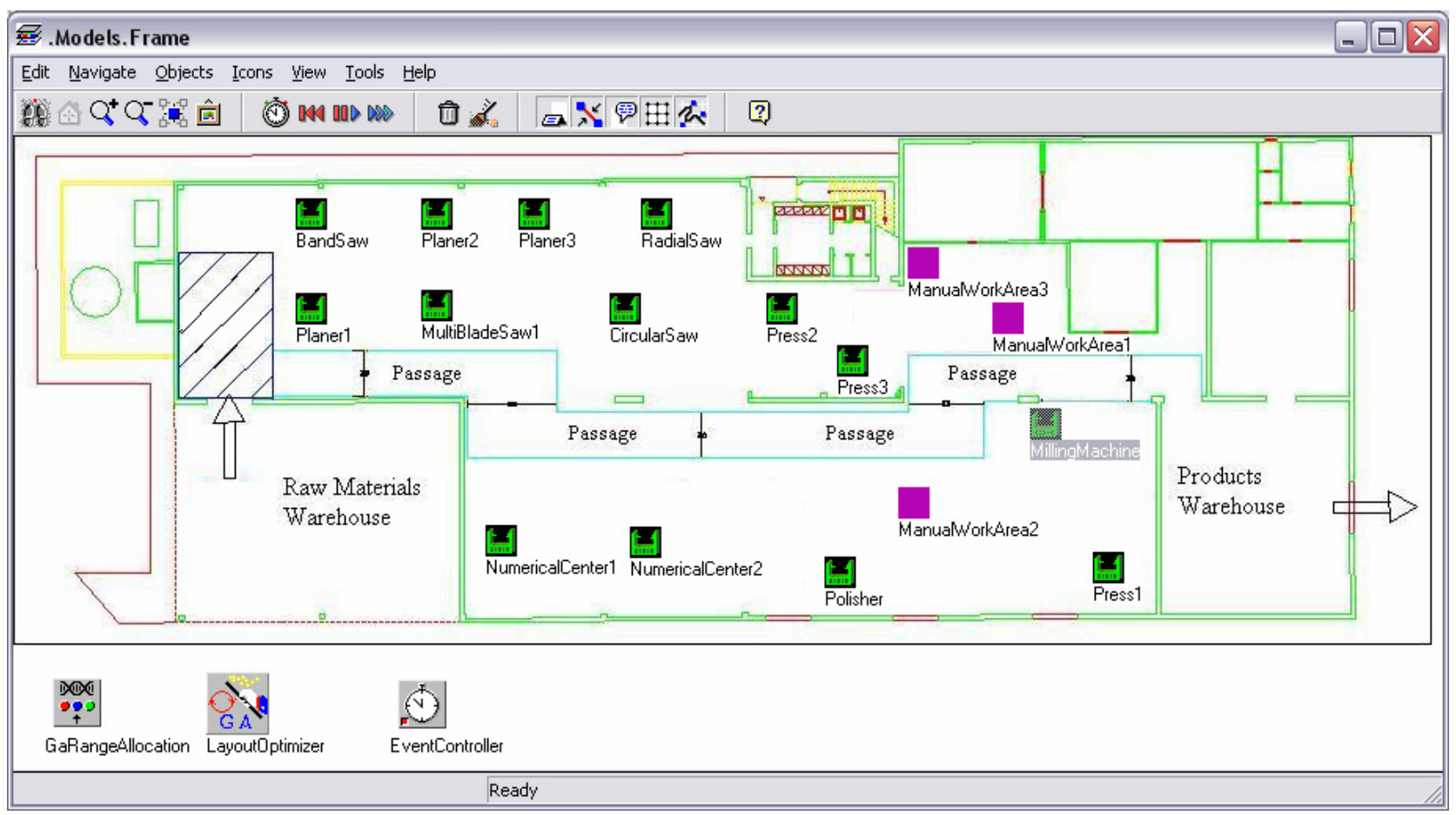

Fig. 7 - Optimal Plant Lay-Out

The simulator verification has been made debugging all the simple ++ code (routines and subroutines) line by line and discussing the implemented logics with the company's experts.

Choosing for each simulation run the length evaluated by means of MSpE analysis and selecting the shop orders scheduling rule used in the real system the validation phase has been started using the Face Validation method. The figure 6 shows the comparison between the real normalized flow time and five simulated normalized flow times. The plot has been shown to the company's experts asking to recognize the real curve and the simulated curves. The experts weren't unable to make such difference obviously testifying the validation of the simulation model.

For what concern the accreditation of the simulation model the attention has been focalized on the entire production of the year 2004. After several simulation runs, the results in output from the model, in terms of simulation time to complete the production have been compared with the real data. In particular, it is important to highlight that the difference between actual and simulated time does not exceed $6 \%$. We concluded that the simulation model is acceptable for material flow analysis and plant lay-out optimization.

\section{PLANT LAY-OUT OPTIMIZATION}

The genetic algorithms have been used to find new and different solutions starting from the initial plant lay-out configuration evaluated by means of traffic intensity methodology and in accordance with production system's experts.

The GAs generate new possible lay-out solutions, each solution is characterized by a value called fitness. The fitness measures the goodness of the solution using the simulation model. In the proposed case, the solution fitness is the material handling cost and the GA goal is fitness minimization in order to find plant lay-out configurations characterized by minimum material handling cost. (The material handling cost obviously depends by materials flow and distances between machines).

The initial solution is shown in fig. 4 and fig. 7 reports one of the optimal solution found by means of GAs.

The validity of the solution proposed by GAs has been tested with several simulation runs under different conditions in terms of demand market trend and variability, comparing the behavior with the initial solution. The results, presented in the remaining paragraphs, regard the material handling cost and shop orders flow time taking into account the following situations:

- high market demand (with high variability);

- high market demand (with low variability);

- low market demand (with high variability);

- low market demand (with low variability).

\section{MATERIAL HANDLING COST ANALYSIS}

The graph in fig. 8 reports the material handling cost (conveniently parameterized) in correspondence of 100 different simulation runs in the case of high 
market demand and high variability. It's important to highlight the difference in terms of material handling cost between the initial plant lay-out configuration and the optimal plant lay-out configuration, with an average reduction of $6.70 \%$.

Better results have been obtained in case of High Demand and Low Variability. Obviously the market demand low variability has a positive impact on the material handling cost (materials flow simplification, better utilization of material handling equipment). The average gain obtained in this case is about $9 \%$, see fig. 9 .

Low Demand and High Variability results are shown in the graph in fig. 10. In this case the material handling cost is lower than the previous cases, due to low market demand (reduction of materials flow). The average material handling cost reduction is about $5 \%$.

The last case (Low Demand, Low Variability) confirms the potentials of the proposed plant lay-out solution, see fig. 11 . The gain is about $8 \%$ (positive effect of the low variability on materials flow).

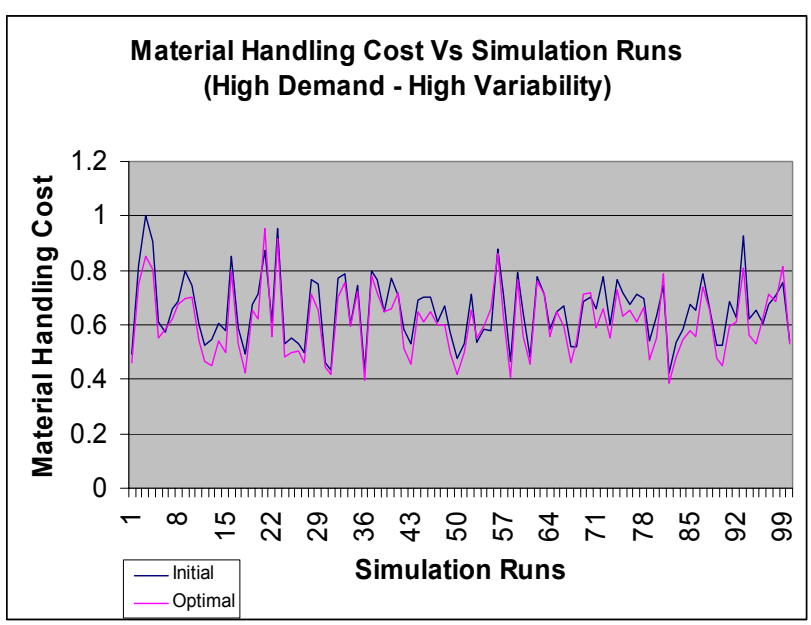

Fig. 8 - Material Handling Cost (High Demand, High Variability)

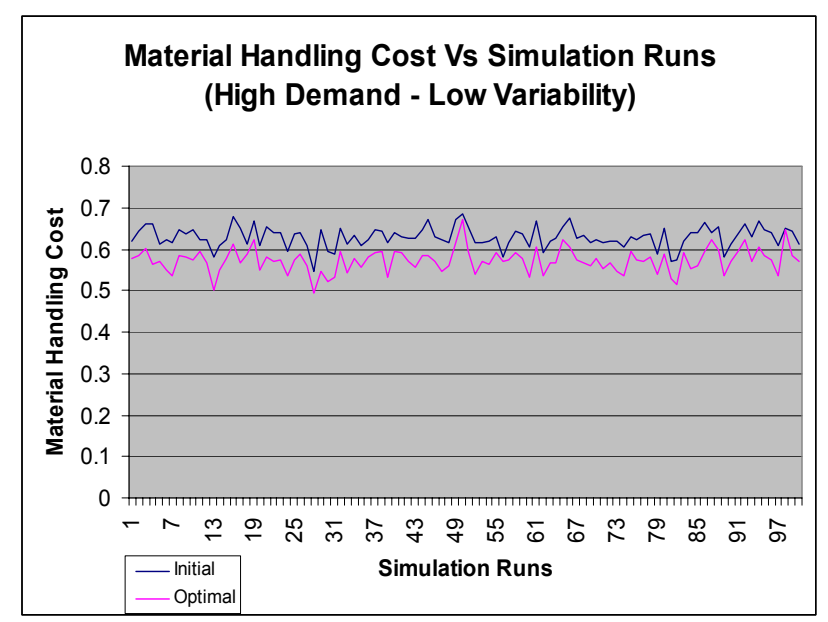

Fig. 9 - Material Handling Cost (High Demand, Low Variability)

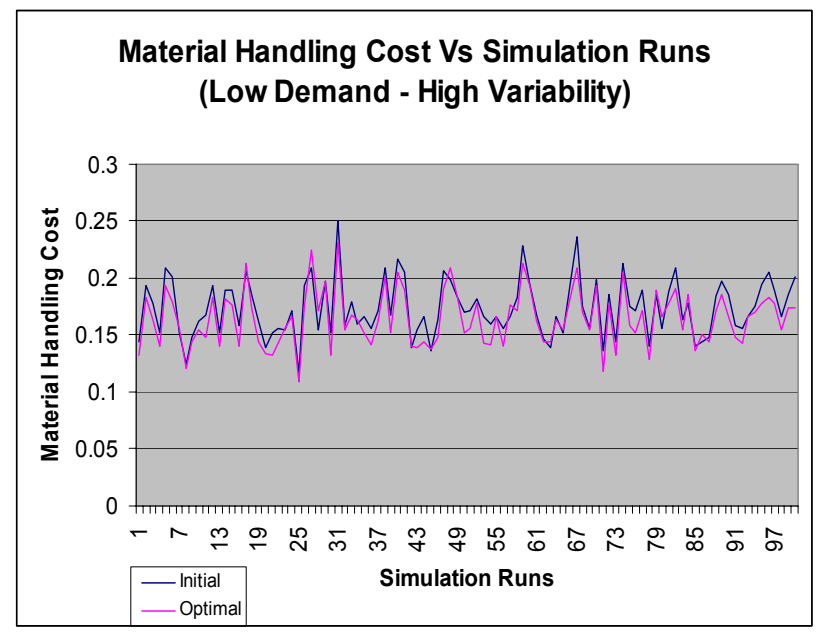

Fig. 10 - Material Handling Cost (Low Demand, High Variability)

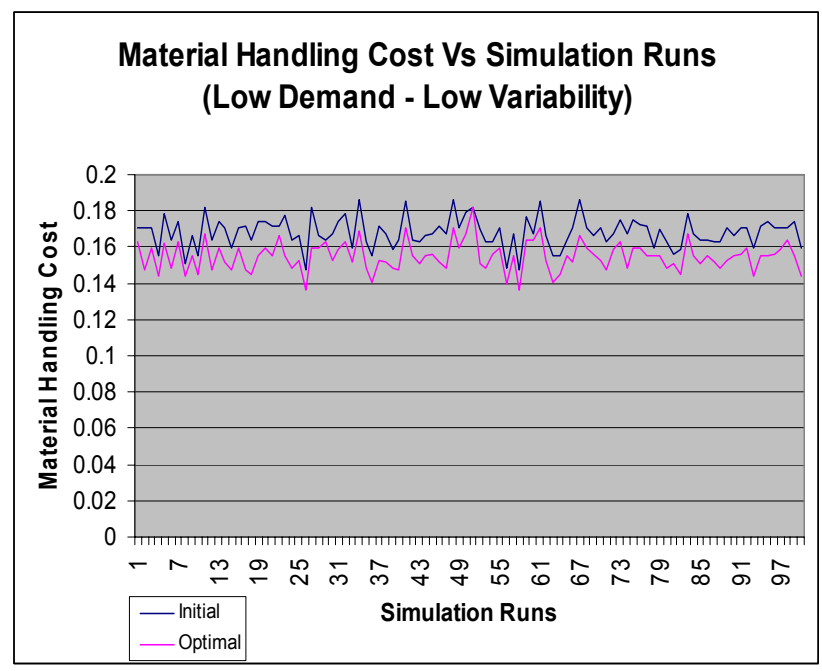

Fig. 11 - Material Handling Cost (Low Demand, Low Variability)

\section{FLOW TIME ANALYSIS}

Materials flow is a major determinant of layout design [6]. The total flow time of the $i$-th shop order $\left(F . T_{.}\right)$can be subdivided in three main components as reported in equation 1 .

$$
F T_{i}=T T_{i}+Q T_{i}+P T_{i}
$$

where $T T_{i}$ Material handling time; $Q T_{i}$ Queue Time; PTi Process Time.

As well know from the theory of production planning and management the Queue Time is strictly related to shop orders scheduling and doesn't depend by plant lay-out organization. The Process Time expresses the time required by machines to perform working operations and it is not affected by machines positions. At last the material handling time depends by plant lay-out organization. 
Because the dependence between lay-out organization and material handling time we can assert the same dependence for shop order flow time. Considering the high importance of flow time minimization (work in process reduction and inventory reduction) the authors conducted several analyses for testing the optimized plant lay-out, found by means of genetic algorithms, monitoring the mean flow time under the effect of different market demand trend and variability. Once again the testing conditions are reported as follows:

- high market demand (with high variability);

- high market demand (with low variability);

- low market demand (with high variability);

- low market demand (with low variability).

The system behavior (considering the new plant lay-out) in correspondence of high market demand shows remarkable reduction of mean flow time. The average gain (mean flow time reduction) is 14.35 hours and 86/100 simulation runs are characterized by flow time reduction. On the contrary the mean flow time augmentation is 7.96 hours and only $14 / 100$ simulation runs show flow time augmentation. Figure 12 reports the mean flow time reduction (green) and augmentation (red) in correspondence of each simulation run. The high data dispersion is due to the high market demand variability.

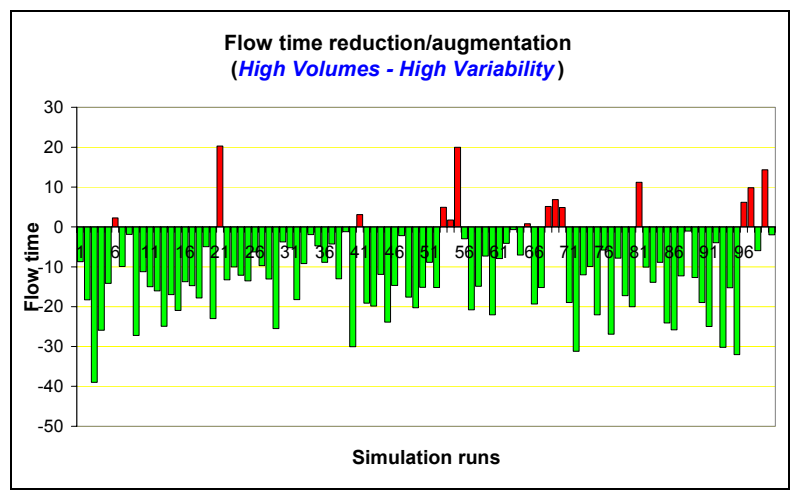

Fig. 12 - Mean Flow Time reduction/augmentation (High Volumes - High Variability)

Better results have been obtained considering high production volumes and low variability. No mean flow time augmentation has been found executing 100 simulation runs. The mean flow time reduction is approximately 14.74 hours. As in the previous case the figure 13 shows the flow time histogram reporting for each simulation run the flow time reduction. The low market demand variability allows a better material handling above all in terms of better material handling systems utilization level.

Even tough the variability effect reduces the plant lay-out efficiency (from 100\% optimized simulation runs to $84 \%$ optimized simulation runs), for sure, we can stress, for the case of high market demand, the validity of the proposed solution.

Let's see now what happens to mean flow time in correspondence of low market demand. The simulation results show an analogous system behavior. The mean flow time reduction is approximately 3.21 hours obtained in correspondence of 81 simulation runs. On the contrary the mean flow time augmentation is 1.45 hours in the remaining 19 simulation runs. Also in this case the high variability has a negative impact on material handling system utilization (see the flow time histogram reported in figure 14).

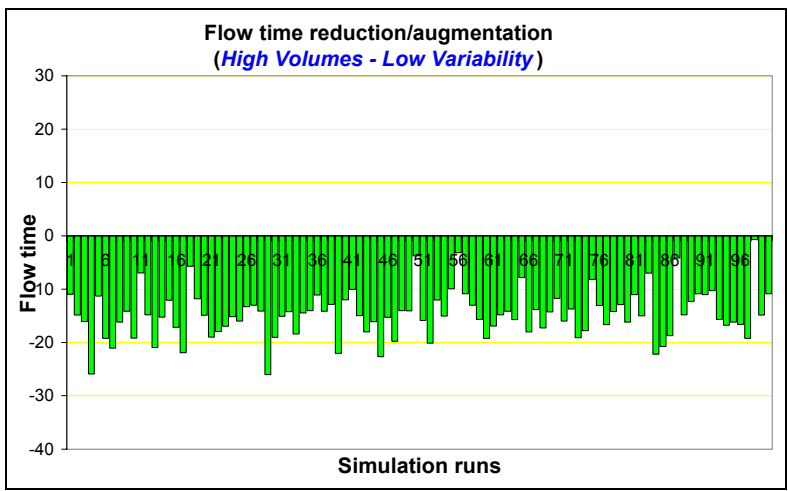

Fig. 13 - Mean Flow Time reduction/augmentation (High Volumes - Low Variability)

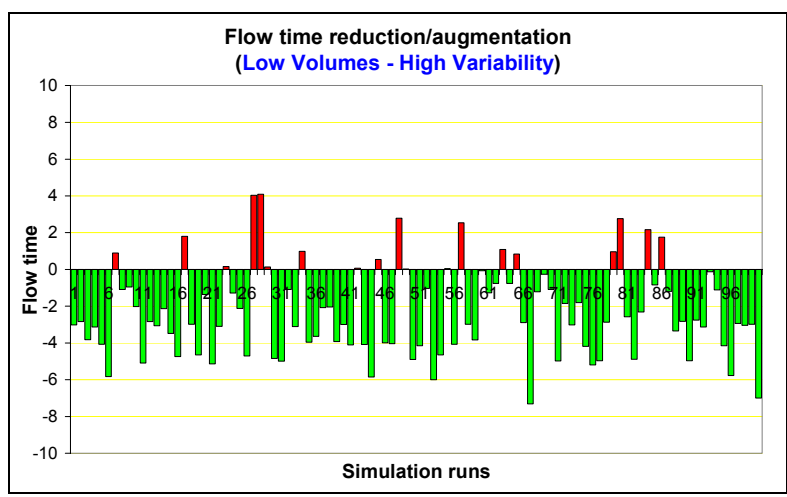

Fig. 14 - Mean Flow Time reduction/augmentation (Low Volumes - High Variability)

The last case (low market demand, low variability) confirms the potentials of the proposed plant lay-out solution. The mean flow time reduction is approximately 3.50 hours and no mean flow time augmentation has been detected in 100 simulation runs. The positive effect of low market demand variability on material handling systems is still confirmed (see fig. 15).

At last it's important to stress both material handling costs and flow time analyses show that the based GAs plant lay-out solution assures optimal results in terms of material handling utilization, work in process and inventory levels. 


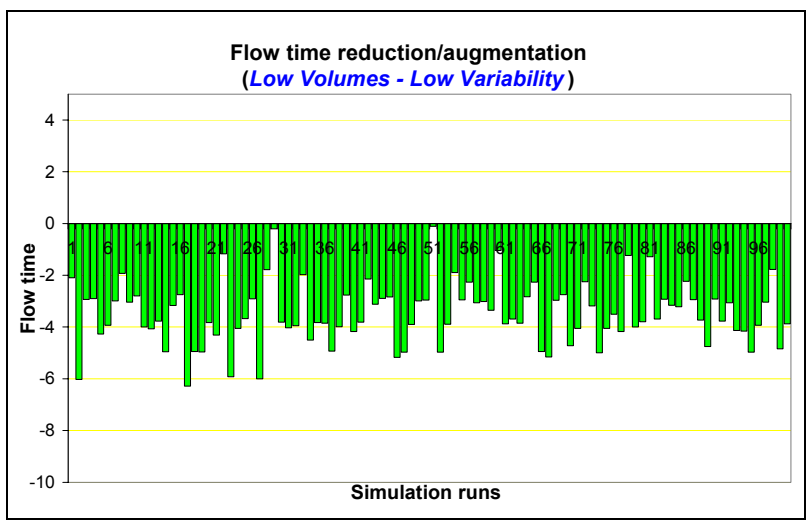

Fig. 15 - Mean Flow Time reduction/augmentation (Low Volumes - Low Variability)

\section{CONCLUSIONS}

The authors focalize on problems concerning with materials flow and lay-out optimization in a manufacturing systems working in the field of wood frames manufacturing.

An initial analysis of the system has been made designing and providing new production documents aiming to data collection and manufacturing process monitoring.

The collected data together with a hypothesis of departments' subdivision have been used to obtain the flow charts of all product families in order to evaluate a plant lay-out initial solution by means of traditional traffic intensity methodology.

The initial solution didn't take into consideration many real aspects such as, for instance, variability in demand market, stochastic process and set-up times. For these reasons the authors decided to construct a simulation model interfaced with genetic algorithms (opportunely modified to by-pass the restrictive assumptions characterizing the GA based object provided by the simulation package).

The VV\&A phase has been conducted by means of Mean Square pure Error analysis, Face Validation and organizing several and different meetings with system's experts.

The simulation model has been used to compare the optimized plant lay-out configuration (obtained using GAs) with the initial one (obtained with the traffic intensity methodology) observing system behavior under the effect of different demands market and variability levels. The results of the material handling costs analysis have shown remarkable costs decrement for the optimal solution. Further analyses regarding the mean shop order flow time have been conducted also to monitor and keep under control work in process and in process inventory levels. The proposed plant lay-out solution allows remarkable mean flow time reduction for each operating conditions (market demand and variability levels).
Finally it's important to stress the validity of the proposed approach. In fact, in this particular case, the simulation model has been used for plant lay-out optimization but it can be used again for short period production planning analyses such as scheduling problems [1] or for inventory management optimization.

\section{REFERENCES}

[1] F. Longo, A. Grande, G. Mirabelli, E. Papoff, Cape applications in special wood frames manufacturing, Proceedings of MITIP Conference, Saarbruecken (Germany), 4/6 September 2003, pp. 31-36.

[2] F. Longo, G. Mirabelli, E. Papoff, Cape Application in special glass manufacturing, Proceedings of IDAACS Conference, Lviv (Ukraine), 8/10 September 2003, pp. 385-389.

[3] F. Longo, G. Mirabelli, E. Papoff, Simulation and optimization of pressure tanks manufacturing process, Proceedings of ANIMP Conference, Rapallo (GE), October 30/31, 2003.

[4] F. Longo, G. Mirabelli, E. Papoff, M. Muzzupappa, Virtual Production Validity (V.P.V.) an Application in the Production Process of Pressure Containers for Motor Vehicles, Proceedings of ISCS Conference, Brindisi, December, 2002.

[5] Banks J., Handbook of simulation, Wiley Interscience.

[6] Zandin K. B., Maynard's Industrial Engineering Handbook, McGraw-Hill, NYC.

[7] Monte, Elementi di Impianti industriali, Edizioni Libreria Cortina Torino, Vol. I, II.

[8] Department of Defense, Deputy Under Secretary of Defense (1994). DoD modeling and simulation $(M \& S)$ management, $D o D$ directive 5000.59.

[9] Hank Grant and Scott Moses, Using Simulation to Evaluate Buffer Adjustment Methods in Order Promising, Proc. of WSC 2002.

[10] Igor Paprotny, Jiun-Yan Shiau, Yo Huh, and Gerald T. Mackulak, Simulation Based Comparison of Semiconductor AMHS Alternatives: Continuous Flow vs. Overhead Monorail, Proc. of WSC 2000.

[11] K. K. Tan and K. Z. Tang, Simulation of an Evolutionary Tuned Fuzzy Dispatching System for Automated Guided Vehicles, Proc. of WSC 2000.

[12] Namdar Bahri and Robert J. Gaskins, Automated Material Handling System Traffic Control by Means of Node Balancing, Proc. of WSC 2000. 
[13] Robert G. Kyle, Jr. and Christopher R. Ludka, Simulation of the Remote Unit Assembly and Test: A Case Study, Proc. of WSC 2000.

[14] Rohit A. Khanolkar, Reducing Gauging Lead Times and Optimizing Layout Design at GM Powertrain with 3D Workcell Simulation, Proc. of WSC 2000.

[15] Gordon D. Rehn, Simulation in Daily Factory Operation: Setting the Line Bogey in Augusta, Proc. of WSC 2000.

[16] Raid Al-Aomar, Product-Mix Analysis with Discrete Event Simulation, Proc. of WSC 2000.

[17] Thomas Schulze, Language Based Simulation Models as Management Tools for Assembly Lines, Proc. of WSC 2000.

[18] Bernard T. Lewis and J. P. Marron, Facilities and Plant Engineering Handbook, McGrawHill, New York, 1973.

[19] Fortenberry, J.C. and Cox, J.F., Multiple criteria approach to the facility layout problem, International Journal of Production Research, 23(4), 773-782.

[20] Kumara, SRT, Kashyap, R.L. and Moodie, C.L.:1988, Application of expert systems and pattern recognition methodologies to facilities layout planning. International Journal of Production Resources, 26(5), 905-930.

[21] Seehof, J.M., and Evans, W.O.:1967, Automated layout design programming, Journal of Industrial Eng., 18(12), 690-695.

[22] Lee, R.C. and Moore, J.M.:1967, CORELAPComputerized relationship layout planning, Industrial Eng., 18(3), 56-61.

[23] Richard Muther and H. Lee Hales, Fundamentals of Plant Floor Layout, Society of Manufacturing Engineers, Dearborn, Michigan, 1998.

[24] Richard Muther and John D. Wheeler, Simplified Systematic Layout Planning, Management \& Industrial Research Publications.

[25] Muther, Jungthirapanich, and Haney, Simplified Systematic Handling Analysis, Management \& Industrial Research Publications.

[26] Richard Muther and Lee Hales, Systematic Planning of Industrial Facilities (SPIF), Management \& Industrial Research Publications, Kansas City, 1980.

[27] Richard Muther, Systematic Layout Planning (SLP) 2nd Edition, Cahners Books, Boston, 1974.

[28] Richard Muther and Knut Haganäs, Systematic Handling Analysis (SHA) Management and Industrial research Publications, Kansas City, Missouri, 1969
[29] H. Lee Hales and Bruce Andersen, Planning Manufacturing Cells, Soc. of Manufacturing Engineers, Dearborn, Michigan, 2002.

[30] H. Lee Hales, Bruce Andersen, and William E. Fillmore, Fundamentals of Manufacturing Cell Planning, Society of Manufacturing Engineers, Dearborn, Michigan, 2002.

[31] Richard Muther, Practical Plant Layout, McGraw-Hill, New York, 1955.

[32] Richard Muther, Production Line Technique, McGraw-Hill, New York, 1944.

[33] H. Lee Hales, Computer-Aided Facilities Planning, Marcel Dekker, Inc., New York, 1984.

[34] Bernard T. Lewis, Management Handbook for Plant Engineers, McGraw-Hill, New York, 1977.

[35] Bernard T. Lewis and J. P. Marron, Facilities and Plant Engineering Handbook, McGrawHill, New York, 1973.

[36] Armour G.C., Gordon C., Computerized relative allocation of facilities technique, Share program catalogue, 1964.

[37] Armour,G.C. and Buffa, E.S.:1963, $A$ heuristic algorithm and computer simulation approach to relative location of facilities, Management Science, 9(1), 294-309.

[38] Dawood, N.N., An integrated knowledgebased / simulation approach to production planning: An application to the pre-cast industry, Construction Management and Economics, 13(1), 53-64.

[39] Fortenberry, J.C. and Cox, J.F., Multiple criteria approach to the facility layout problem, International Journal of Production Research, 23(4), 773-782, 1985.

[40] Kumara, SRT, Kashyap, R.L. and Moodie, C.L., Application of expert systems and pattern recognition methodologies to facilities layout planning. International Journal of Production Resources, 26(5), 905-930, 1982.

[41] Rosenbaltt, M.J., The facilities layout problem: a multi goal approach, International Journal of Production Research, 17, 323-332, 1979.

[42] Sulaiman,M.J., InteSite: An intelligent site layout planning within an object oriented integrated construction environment, $\mathrm{PhD}$ Dissertation, University of Salford, Salford, UK, 1997.

[43] Williams, M., Graphical simulation for project planning: 4D-Planner, in Jorge Vanegas and Paul Chinowsky (eds.), Computing in Civil Engineering, ASCE, Proc. of 3rd Congress, June 17-19, 1996. 


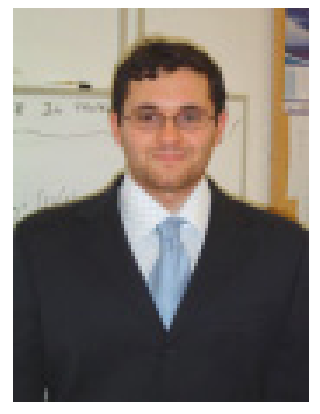

Longo Francesco was born in Crotone (Italy), on February the $08^{\text {th }}, 1979$. He took the degree in Mechanical Engineering from University of Calabria (2002) and the $\mathrm{PhD}$ in Industrial Engineering (2005). $\mathrm{He}$ is currently researcher at the Mechanical Department (Industrial Engineering Section) of University of Calabria. His research interests regard modeling \& simulation of manufacturing systems and supply chain, DOE, ANOVA.

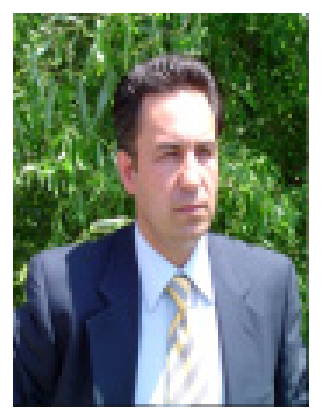

Giovanni Mirabelli was born in Rende (Italy), on January the $24^{\text {th }}$, 1963. He took the degree in Industrial Technology Engineering from University of Calabria. $\mathrm{He}$ is currently researcher at the Mechanical Department (Industrial Engineering Section) of University of Calabria. His research interests regard work measurement and human reliability.

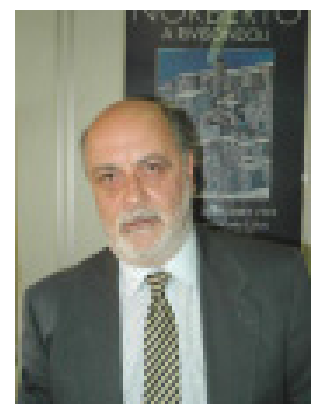

Papoff Enrico was born in Naples (Italy) on February the $03^{r d}$, 1948. He took the degree in Mechanical Engineering from University of Napoli Federico II, in 1973. $\mathrm{He}$ is currently Associate Professor at the Mechanical Department (Industrial Engineering Section) of the University of Calabria. His research interests regard project management and business plans. 